\title{
Can physical activity compensate for low socioeconomic status with regard to poor self-rated health and low quality-of-life?
}

\author{
Lisbeth M. Johansson ${ }^{1 *}$, Hans Lingfors ${ }^{1,2}$, Marie Golsäter ${ }^{4,1,2}$, Margareta Kristenson ${ }^{5}$ and Eleonor I. Fransson 1,2,3,6
}

\begin{abstract}
Background: Both high socioeconomic status (SES) and high physical activity (PA) are associated with better self-rated health (SRH) and higher quality-of-life (QoL).

Aim: To investigate whether high levels of PA may compensate for the association between low SES and subjective health outcomes in terms of poorer SRH and lower QoL.

Method: Data from a cross-sectional, population-based study $(n=5326)$ was utilized. Multiple logistic regression models were used to estimate odds ratios (OR) and 95\% confidence intervals (95\% Cl) for the associations between indicators of SES (economic situation and educational level), SRH and QoL, as well as between the combination of SES and PA in relation to SRH and QoL.

Result: Participants with high PA and economic problems had approximately the same OR for good SRH as those with low PA and without economic problems (OR 1.75 [95\% Cl 1.20-2.54] and 1.81 [1.25-2.63] respectively). Participants with high PA and low education had higher odds for good SRH (OR 3.34 [2.96-5.34] compared to those with low PA and high education (OR 1.46 [0.89-2.39]).Those with high PA and economic problems had an OR of 2.09 [1.42-3.08], for high QoL, while the corresponding OR for those with low PA and without economic problems was 4.38 [2.89-6.63].
\end{abstract}

Conclusion: Physically active people with low SES, had the same or even better odds to report good SRH compared to those with low PA and high SES. For QoL the result was not as consistent. The findings highlight the potential for promotion of PA to reduce SES-based inequalities in SRH.

Keywords: Physical activity, Health dialogue, Socioeconomic status, Self-rated health, Quality-of-life

\section{Introduction}

The relationship between socioeconomic status (SES) and health outcomes in terms of self-rated health (SRH) and quality-of- life (QoL) is well established all over the world [1-4]. These associations have been demonstrated for several indicators of SES for example economic situation and educational level, where both economic problems and low education have been shown to be associated with poorer SRH and lower QoL $[3,5,6]$. Notably, over the past decades SES differences in SRH

\footnotetext{
* Correspondence: lisbeth.m.johansson@rjl.se

${ }^{1}$ Unit for Research and Development in Primary Health Care, Futurum -

Academy for Health and Care, Region Jönköping County, Jönköping,

Sweden

Full list of author information is available at the end of the article
}

have increased in several countries including Sweden $[7,8]$. SRH and QoL are both subjective measures that also indicate the general state of health and wellbeing. However these measures are not equivalent nor interchangeable [9]. SRH reflects an individual's general perception of health, including biological, social and psychological dimensions $[10,11]$. QoL is a broader concept including several dimensions of life such as material resources, social functioning and social relationships, well-being, happiness, and life satisfaction [9]. Beyond the importance of a good SRH and a high QoL in and of themselves, there is also extensive evidence that SRH and QoL are potent predictors for future morbidity and survival/mortality [12-14].

(c) The Author(s). 2019 Open Access This article is distributed under the terms of the Creative Commons Attribution 4.0 International License (http://creativecommons.org/licenses/by/4.0/), which permits unrestricted use, distribution, and reproduction in any medium, provided you give appropriate credit to the original author(s) and the source, provide a link to the Creative Commons license, and indicate if changes were made. The Creative Commons Public Domain Dedication waiver (http://creativecommons.org/publicdomain/zero/1.0/) applies to the data made available in this article, unless otherwise stated. 
Physical activity (PA) is defined as all physical activities performed by skeletal muscles that result in increased energy consumption above basal metabolic rate [15]. PA is one of the major lifestyle factors that, in addition to smoking, dietary habits and alcohol intake have a great impact on health and non-communicable diseases, for example cardiovascular disease (CVD), diabetes and cancer, as well as all-cause mortality [16-18]. In the European Region it has been estimated that lifestyle related diseases contribute to $77 \%$ of the non-communicable disease burden and $86 \%$ of all deaths [16]. High PA is also associated with a higher level of SRH and QoL [19-22]. Low PA is very common globally [23] and in Sweden a third of adults are insufficiently active according to a recent national public health survey [24]. This is especially pronounced among people with low SES, who generally report lower levels of both leisure-time PA and commuting to work PA, and also report a more sedentary behaviour [25]. Low PA could therefore be one explanation for poorer SRH and lower QoL in the groups with low SES and it is of interest to study if a higher level of PA can compensate for the observed differences in SRH and QoL related to SES $[12,26]$.

\section{Aim}

The aim of this study is to investigate whether high levels of PA may compensate for the association between low SES and subjective health outcomes in terms of poorer SRH and lower QoL.

\section{Material and method}

\section{Setting and data collection}

This study is a part of the Living Condition Stress and Health (LSH) study which aims to prospectively evaluate causes for socioeconomic differences in health. In the present cross-sectional study, baseline data from the LSH study were used. The data were collected between 2012 and 2015 in the southeast part of Sweden. The study population includes a random sample of people aged $40,45,50,55,60,65$ and 70 years who were invited to their primary health care centre (PHCC) for a health dialogue. Those who took part in the health dialogues were also invited to participate in the LSH study. Details of the health dialogue procedure have been described elsewhere [27-29]. Compared to the standard health dialogue procedure, taking part in the LSH study included answering one additional questionnaire and providing an additional blood sample. Of the 28,702 invited people, $12,164(42 \%)$ accepted to take part in a health dialogue and of those 6860 (56\%) individuals (3880 women and 2980 men) also participated in the LSH study. The mean age was 54 years (SD of 9.9 years). Compared with data, for the general population in southeast part Sweden the LSH study population was representative regarding educational level but men aged 40 years and immigrants were slightly underrepresented.

\section{Analytical sample}

For the present analysis, participants were excluded if they reported any of the following diagnoses (as given by a physician) as they could have a negative impact on the participants' ability to take part in PA. The diagnoses comprised myocardial infarction or stroke, angina pectoris, chronic lung disease, rheumatoid arthritis, musculoskeletal disorders, neurological disease and depression. Out of 6860 participants, 1532 had one or more of these diseases and two participants had not answered the questions of interest for this study. After exclusion, 5326 participants remained in the analytical sample for this study.

\section{Indicators of socioeconomic status (SES)}

In this study, economic situation and educational level were chosen as indicators of SES; both retrieved from the questionnaires. The question about perceived economic situation was formulated as "Is the economy a problem for you?" with three answer options. The responses to this question were dichotomised where the answers "partly" and "yes" were combined into "Economic problem" and the answer "no" was labelled as "No economic problem".

Education was measured in terms of highest achieved education and responses were divided into three levels: "Elementary school" was categorized as "Low education"; "Two-year high-school/vocational school, girls' school, secondary school or equal, three-or-four-year highschool" was categorized as "Intermediate education"; and "University degree" was categorized as "High education".

\section{Physical activity (PA)}

PA scores were calculated from responses to two different questionnaires about PA during leisure-time and PA commuting to work. The health dialogue performer also asked supplementary questions, which means that the measurement of PA was a combination of a questionnaire and an interview. Responses were transferred into PA "points" representing the level of PA. Further details concerning questionnaires and the calculation of PA score can be found in Additional file 1 and have been described elsewhere [27]. In this study, three levels of PA were defined, where 0-499 points denotes low PA, 500-999 points denotes intermediate PA and 1000 or more points (corresponding to at least $30 \mathrm{~min}$ of brisk walk per day) denotes high PA.

\section{Combined variables of PA and SES}

Two combined variables based on PA and SES were created. The first variable was the combination of PA (low, intermediate, or high PA) and economic situation 
(economic problems or no economic problems). The other variable consisted of the combination of PA (low, intermediate or high PA) and education level, (low, intermediate or high education).

\section{Outcome variables, SRH and QoL}

In the questionnaires there was one question about SRH; "How do you rate your general health status?" with five response alternatives. The answers to this question were dichotomised, where the answers "good" and "very good" were categorized as "good SRH" and the answers "fairly good", "bad" and "very bad" were categorized as "poor SRH” [30-32].

The Cantril's Self-Anchoring Scale "The Ladder of Life" [27], was used as an indicator of QoL. This is a global measure of QoL which has steps 0-10 where participants are asked to mark which step of the ladder of life they are standing on at the time of the data collection [33]. The top step (ten) represents the best possible life, and the bottom step (zero) represents the worst possible life [33]. In common with other studies the steps in this study between zero and ten were dichotomised, where steps zero to five were defined as "low QoL" and six to ten were defined as "high QoL" [34, 35].

\section{Potential confounders}

Sex, age, smoking and food quality were considered as potential confounding variables since it is well known that they are associated with SES and PA, as well as with SRH and QoL. Age was divided into seven age groups: $40,45,50,55,60,65$ and 70 years old (the same as the recruitment groups).

The question about smoking habits had five response alternatives that were used in the analyses "I have never smoked", "I stopped smoking more than 6 months ago", "I stopped smoking less than 6 months ago", "I smoke but not daily" and "I smoke daily".

Food quality was captured from the questionnaire " 20 questions about your food habits" that estimated the intake of hard fats, fibre and sugar. Further details concerning this measure of food quality have been described elsewhere [27]. In this study three levels of food quality were defined, where $3-5$ points mean high food quality (characterised by a low intake of hard fat and a high fibre intake), 6-8 points intermediate food quality and 9-11 points depicts low food quality (characterised by a high intake of hard fat and a low fibre intake).

\section{Statistical analyses}

Descriptive statistics were used to describe the background characteristics of the participants. Logistic regression analysis was used to estimate odds ratios (OR) with 95\% confidence intervals $(95 \% \mathrm{CI})$, to describe the associations between the indicators of SES (economic situation and educational level) and PA respectively and the outcome variables SRH or QoL. Both unadjusted estimates (Model I) and estimates adjusted for sex, age, smoking and food quality (Model II) were derived.

We also conducted stratified analyses where the association between SES indicators and the outcomes were analysed stratified by physical activity level. Interaction between SES indicators and PA was evaluated by a SES $x$ PA interaction term in the respective model.

In the next step, the combined variables of the SES indicators and PA were analysed in logistic regression models to evaluate if a high level of PA could compensate for low SES with regards to SRH and QoL. The estimates were adjusted for sex, age, smoking and food quality. All analyses were performed using SPSS version 24 and 25 (IBM Corp, Armonk, New York, USA).

\section{Ethical issues}

The study received ethical approval from the regional ethical review board in Linköping (\# 2012/336-32). All participants were properly informed about all study procedures and they gave written informed consent to participate in the study. The study is conducted in accordance with the guidelines of the Declaration of Helsinki.

\section{Results}

\section{Characteristics of the study population}

Characteristics of the 5326 participants included in the current analysis are summarised in Table 1, where also the indicators for PA and SES as well as the outcome variables SRH and QoL are also presented. The mean age for the participants included in the analysis was 52.9 (SD 9.7) years. The proportion of smokers was 9.2, and $21.1 \%$ were categorized in the low food quality category. The proportion of participants with high PA was $69.4 \%$, the proportion with good SRH was $78,0 \%$, and the proportion with high QoL was $88.3 \%$.

\section{Associations between exposure variables and outcome variables}

The unadjusted associations between the exposure variables economic situation, educational level or PA and the outcome variables SRH or QoL are shown in Table 2 (Model I). Among those with no economic problems or high education there were higher odds for good SRH compared to participants with economic problems or Low education (OR 3.26 [95\% CI 2.79-3.81] and 1.85 [95\% CI 1.51-2.28] respectively). Among those with high PA there were also, compared with those with low PA, higher odds for good SRH (OR 3.25 [95\% CI 2.72-3.88). The same pattern was observed for QoL in the unadjusted analyses (Model I): there were higher odds among those with no economic problems, high education or high PA level to report high QoL 
Table 1 Background characteristics of included participant. The LSH study

\begin{tabular}{|c|c|c|c|}
\hline Variable & Characteristics & $n$ & Percent \\
\hline \multirow[t]{2}{*}{ Sex } & Male & 2404 & 45.1 \\
\hline & Female & 2922 & 54.9 \\
\hline \multirow[t]{7}{*}{ Age } & 40 years & 1186 & 22.3 \\
\hline & 45 years & 419 & 7.9 \\
\hline & 50 years & 1275 & 23.9 \\
\hline & 55 years & 386 & 7.2 \\
\hline & 60 years & 1181 & 22.2 \\
\hline & 65 years & 368 & 6.9 \\
\hline & 70 years & 511 & 9.6 \\
\hline \multirow[t]{5}{*}{ Smoking habits } & Never smoked & 3209 & 61.2 \\
\hline & Stopped $>6$ months ago & 1516 & 28.9 \\
\hline & Stopped < 6 months ago & 36 & 0.7 \\
\hline & Smokes but not daily & 148 & 2.8 \\
\hline & Daily smoker & 338 & 6.4 \\
\hline \multirow[t]{3}{*}{ Food habits } & High food quality: & 2174 & 43.9 \\
\hline & Intermediate food quality: & 1730 & 35,0 \\
\hline & Low food quality: & 1047 & 21.1 \\
\hline \multirow[t]{2}{*}{ Economic situation } & No economic problem & 4363 & 83.2 \\
\hline & Economic problem & 884 & 16.8 \\
\hline \multirow[t]{3}{*}{ Educational level } & Long education & 1883 & 37.5 \\
\hline & Intermediate education & 2470 & 49.1 \\
\hline & Short education & 674 & 13.4 \\
\hline \multirow[t]{3}{*}{ Physical Activity (PA) } & High PA & 3469 & 69.4 \\
\hline & Intermediate PA & 845 & 16.9 \\
\hline & Low PA & 682 & 13.7 \\
\hline \multirow[t]{2}{*}{ Self-Rated-Health (SRH) } & Good SRH & 4071 & 78.3 \\
\hline & Poor SRH & 1130 & 21.7 \\
\hline \multirow[t]{2}{*}{ Quality-of-Life (QoL) } & High QoL & 4540 & 88.3 \\
\hline & Low QoL & 600 & 11.7 \\
\hline
\end{tabular}

compared to participants with, economic problems, low educational level or low PA (Table 2).

After adjusting for sex, age, smoking habits, and food quality, the associations between economic situation, educational level, or PA and the outcome variable SRH remained strong (Model II, Table 2). Participants who reported no economic problems or high PA had approximately three times higher odds of having good SRH compared with those who reported economic problems or low PA (OR 3.0 [95\% CI 2.54-3.55] and OR 3.13[95\% CI 2.59-3.78] respectively). Having a high education, compared to low education, was also associated with higher odds for good SRH (OR 1.57 [95\% CI 1.25-1.98]) (Table 2). For economic situation and PA the same pattern was noted for QoL, where the odds for high QoL, after adjustment, were almost five times higher for those with no economic problems compared with those who reported economic problems (OR 4.95 [95\% CI 4.06-6.03]) and more than two times higher for those with high PA compared with those with low PA (OR 2.37 [95\% CI 1.88-2.99]). However, after adjustment no statistically significant association was seen between educational level and QoL (Table 2).

\section{Associations between socioeconomic status and outcome variables stratified by PA level}

The associations between SES and the outcome variables stratified by PA levels are shown in Additional file 2 . The stratified analyses showed a strong association between economic situation and both SRH and QoL in all PA strata. The associations between education and the outcomes are not as strong. When testing for statistical interaction the only statistically significant interaction between SES indicator and PA was observed for economic situation in relation to SRH (Additional file 2).

Associations between combinations of exposure variables and outcome variables

The odds for the for combinations of PA and SES (economic situation or educational level) in relation to the studied outcomes, adjusted for sex, age, smoking habits, and food quality are shown in Figs. 1 and $2(\mathrm{SRH})$ and Figs. 3 and 4 (QoL). Those with high PA and no economic problems had the highest odds to have good SRH (OR 6.36 [95\% CI 4.53-8.94]) compared with the groups with low PA and economic problems. Furthermore, those with high PA who reported economic problems had approximately the same odds to have good SRH as those with low PA and without economic problems (OR 1.75 [95\% CI 1.20-2.54] and OR 1.81 [95\% CI 1.25-2.63], respectively) (Fig. 1).

High PA was also associated with higher odds for good $\mathrm{SRH}$, in each group of educational level. Those with high PA and high education had the highest odds of having good SRH (OR 4.53 [95\% CI 2.96-6.95]) (Fig. 2). Those with high PA and low education had higher odds for good SRH (OR 3.34 [95\% CI 2.09-5.34] compared to those with low PA and long education (OR 1.46 [95\% CI 0.89-2.39]) (Fig. 2) although the confidence intervals slightly overlapping.

The Highest odds for high QoL were observed for the groups with no economic problems and intermediate or high PA (Fig. 3), the OR for high QoL was 2.09 [95\% CI 1.42-3.08], for those with high PA and economic problems compared with those with low PA and economic problems while the corresponding OR for the group with low PA and no economic problems was 4.38 [95\% CI 2.89-6.63] (Fig. 3).

When combining PA with educational level the estimated ORs for high QoL are similar for those with high PA and low education (OR 3.35 [95\% CI 1.86-6.04]), compared to participants with high PA and high education 
Table 2 The associations between indicators of SES and PA, and good SRH and high QoL. Unadjusted Odds Ratios (OR) with 95\% confidence intervals $(95 \% \mathrm{Cl}$ ) in Model I and adjusted for sex, age, smoking habits, and food quality in Model II. The LSH study

\begin{tabular}{|c|c|c|c|c|c|c|c|c|}
\hline \multirow[b]{2}{*}{ SES } & \multicolumn{4}{|c|}{ OR for good SRH } & \multicolumn{4}{|c|}{ OR for high QoL } \\
\hline & $\begin{array}{l}\mathrm{N}(\% \text { good } \\
\text { SRH) }\end{array}$ & SRH MODEL I & $\begin{array}{l}\text { N (\% good } \\
\text { SRH) }\end{array}$ & SRH/MODEL II & $\begin{array}{l}\text { N (\% high } \\
\text { QoL) }\end{array}$ & QoL MODEL I & $\begin{array}{l}\text { N (\% high } \\
\text { QoL) }\end{array}$ & QoL/MODEL ॥ \\
\hline Economic situation & 5169 & & 4792 & & 5111 & & 4741 & \\
\hline Economic problem & $867(59)$ & 1 ref & $783(59)$ & 1 ref & $853(69)$ & 1 ref & $770(69)$ & 1 ref. \\
\hline $\begin{array}{l}\text { No economic } \\
\text { problem }\end{array}$ & $4302(82)$ & $\begin{array}{l}3.26(2.79- \\
3.81)\end{array}$ & 4009 (82) & $\begin{array}{l}3.0(2.54- \\
3.55)\end{array}$ & $4258(92)$ & $\begin{array}{l}5.41(4.51- \\
6.51)\end{array}$ & 3971 (92) & $\begin{array}{l}4.95(4.06- \\
6.03)\end{array}$ \\
\hline Education level & 4930 & & 4572 & & 4881 & & 4530 & \\
\hline Short education & $659(71)$ & 1 ref & $607(72)$ & 1 ref & $645(87)$ & 1 ref & $595(87)$ & 1 ref. \\
\hline $\begin{array}{l}\text { Intermediate } \\
\text { education }\end{array}$ & $2426(78)$ & $\begin{array}{l}1.47(1.22- \\
1.79)\end{array}$ & $2249(78)$ & $\begin{array}{l}1.35(1.09- \\
1.67)\end{array}$ & $2392(88)$ & $\begin{array}{l}1.14(0.88- \\
1.47)\end{array}$ & $2220(88)$ & $\begin{array}{l}1.1(0.83- \\
1.47)\end{array}$ \\
\hline Long education & $1845(82)$ & $\begin{array}{l}1.85(1.51- \\
2.28)\end{array}$ & $1716(82)$ & $\begin{array}{l}1.57(1.25- \\
1.98)\end{array}$ & $1844(90)$ & $\begin{array}{l}1.43(1.09- \\
1.88)\end{array}$ & $1715(90)$ & $\begin{array}{l}1.27(0.93- \\
1.73)\end{array}$ \\
\hline Physical activity level & 4894 & & 4541 & & 4842 & & 4497 & \\
\hline Low PA & $671(60)$ & 1 ref & $628(60)$ & 1 ref. & $664(78)$ & 1 ref & $623(78)$ & 1 ref. \\
\hline Intermediate PA & $820(76)$ & $\begin{array}{l}2.13(1.71- \\
2.66)\end{array}$ & $753(75)$ & $\begin{array}{l}1.91(1.51- \\
2.42)\end{array}$ & $816(88)$ & $\begin{array}{l}2.18(1.65- \\
2.90)\end{array}$ & $747(89)$ & $\begin{array}{l}2.05(1.52- \\
2.77)\end{array}$ \\
\hline High PA & 3403 (83) & $\begin{array}{l}3.25(2.72- \\
3.88)\end{array}$ & 3160 (83) & $\begin{array}{l}3.13(2.59- \\
3.78)\end{array}$ & $3362(90)$ & $\begin{array}{l}2.70(2.18- \\
3.36)\end{array}$ & 3127 (91) & $\begin{array}{l}2.37(1.88- \\
2.99)\end{array}$ \\
\hline
\end{tabular}

(OR 3.08 [95\% CI 1.87-5.08]) (Fig. 4). Furthermore those with high PA and low education tend to have higher odds for reporting high QoL, as compared with the group with low PA and high education (OR 3.35 [95\% CI 1.86-6.04] vs. OR 1.26 [95\% CI $0.71-2.25$ ] (Fig. 4) although the confidence intervals are overlapping.

\section{Discussion}

In this cross-sectional population-based study we found strong associations between both SES (in terms of economic situation or educational level), and PA, with the outcomes SRH and QoL when analysed one by one. As expected booth high SES and higher levels of PA were observed for the combination of good SRH and high

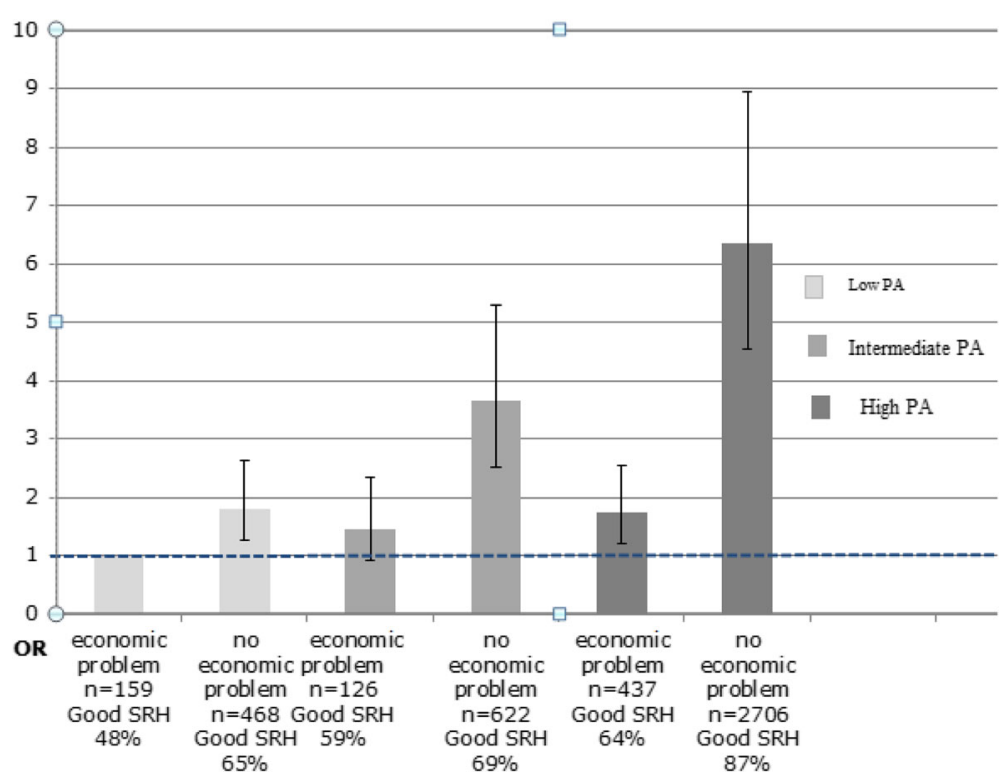

Fig. 1 Combination of economic situation and PA, Odds ratio (OR) for good SRH. OR with 95\%confidence intervals (95\% Cl) adjusted for sex, age, smoking habits, and food quality. The LSH study 


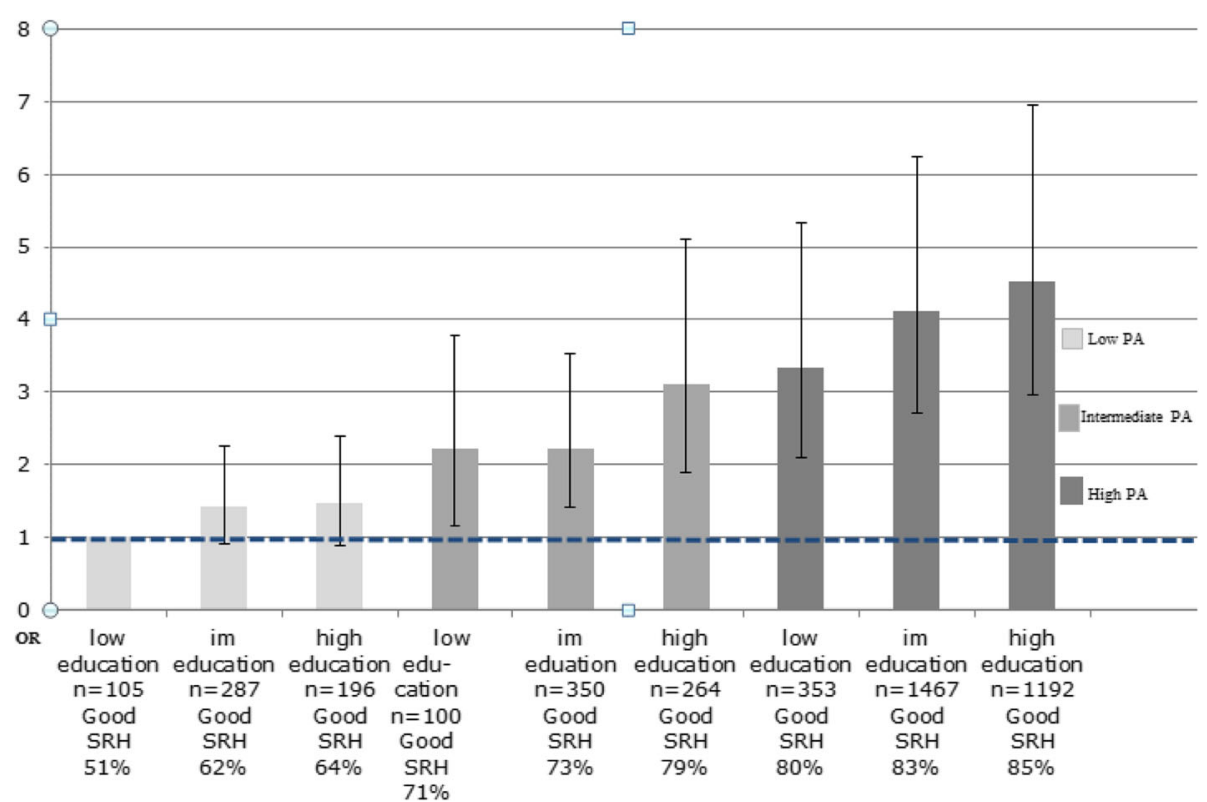

Fig. 2 Combination of educational level and PA, Odds Ratios (OR) for good SRH. OR with 95\% confidence intervals (95\% Cl) adjusted for sex, age, smoking habits, and food quality. The LSH study im = intermediate

QoL. We also found that high PA almost offset the lower odds for good SRH, observed in groups with economic problems or with low education. However for QoL the result was not as consistent.

Our results regarding the separate associations for SES and PA in relation to SRH are in line with earlier studies that have shown that PA is related to better $\mathrm{SRH}[20]$ and that economic problems are associated with poorer SRH [36, 37]. However, to our knowledge, this is the first study to illustrate that PA may compensate for SES with regard to SRH and QoL in these age groups. Associations between economic problems and low QoL have also been observed previously [38]. Our results suggest that there is also a potential for individuals with low education to improve their QoL with PA.






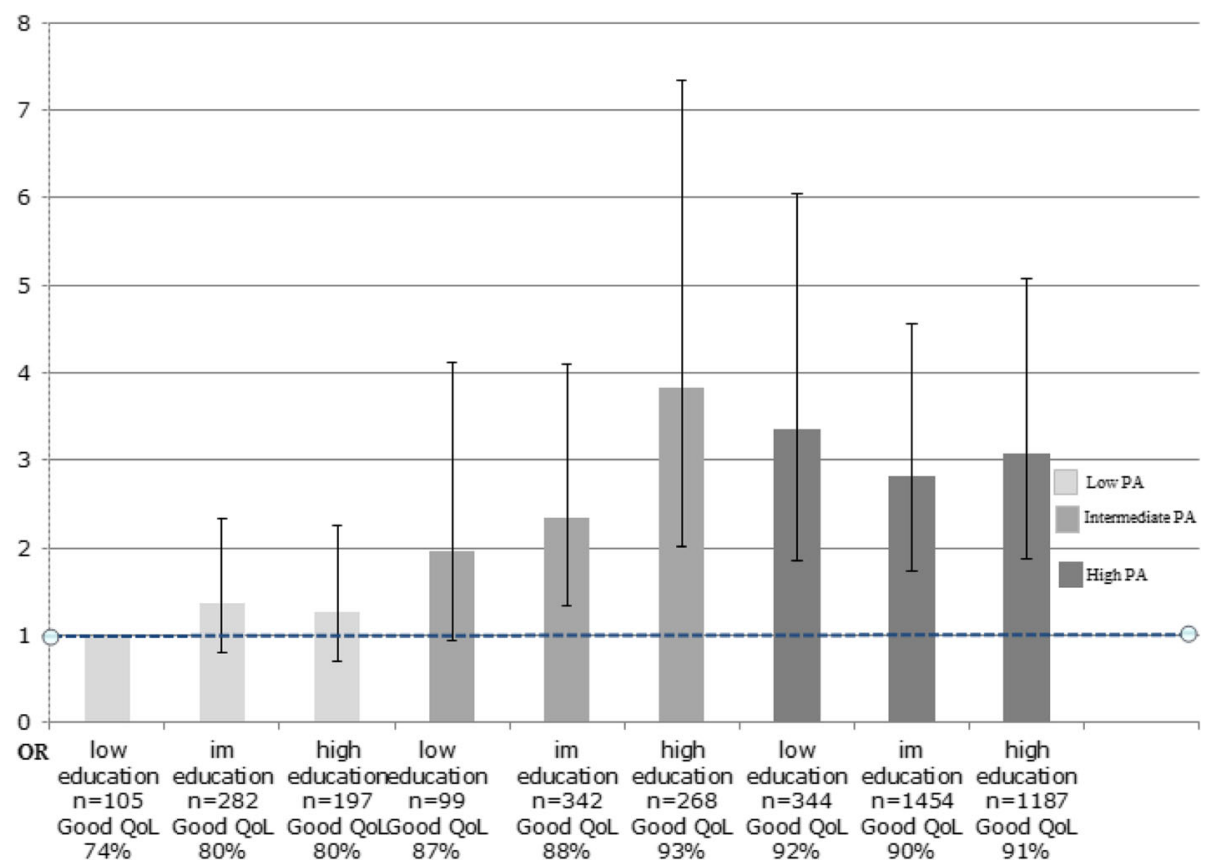

Fig. 4 Combination of educational level and PA, Odds Ratios (OR) for high QoL. OR with 95\% confidence intervals (95\% Cl) adjusted for sex, age, smoking habits, and food quality. The LSH study im = intermediate

Moreover, the odds for good SRH increased with higher level of PA in each educational level group and participants with high PA and low education reported good SRH to the same extent, as those with low PA and high education. These results are consistent with results from a study from Germany that includes older people [39].

Our results thus highlight the potential value of increasing PA to achieve good SRH both in groups with economic problems and in groups with low education. $\mathrm{SRH}$ is a composite measure known to be affected by both biological and social factors as well as psychological resources $[10,11]$. The causes of these effects can be traced by known associations of high PA with decreased risk of several somatic diseases, but also with better mental health, improved memory functions and creative thinking [22, 40-42]. Furthermore high PA may reduce the detrimental effects of stress, improve optimism and prevent depression [43-46]. PA has been linked to salutogenesis and enhanced sense of coherence [47]. PA is also known to be related to higher QoL [42], which we also observed in this study. We found some association between economic situation and QoL but this association was not as consistent as for SRH. When combining educational level with PA the OR for high QoL, is equal or even higher for those with low education and high PA, compared with those with high education and high PA. One possible reason for slightly different results regarding SRH and QoL could be that SRH and QoL are two different aspects of the patient's subjective experiences. QoL is a broader concept in which SRH only is one among many components.

The salutogenic theory, points out the importance of one's own health resources and the salutogenic perspective is important in health promotion work, as a means to identify individual's own resources to improve or maintain their health [48]. One concept that has been derived from the umbrella of the salutogenic perspective is self-efficacy [49], which means specific confidence to one's own ability to change a specific lifestyle habit such as PA. This may be useful when supporting the efforts of individuals to achieve a higher level of PA [50,51]. Our results provide additional evidence for the importance of supporting individuals especially those with low SES, to achieve a higher level of PA for a better SRH and higher QoL.

\section{Strengths and limitations}

One strength of this study is that it is a well-characterised population-based study, comprising a large number of participants that are representative for the adult population as well as considering both women and men between 40 and 70 years of age. Another important strength of the study is that the included questionnaires have shown to have good validity for example for education [24], PA [52], SRH [53], for food habits [54] and smoking habits [55]. The questionnaires have also been used in several other studies prior to this one, which increases comparability between studies. We have used Cantril's ladder of life as an indicator of QoL [33] as others have done before 
[56-58]. This scale has also been used to measure the closely related concept life satisfaction [59].

In the analysis we have categorised different exposure and outcome variables which were based on different scales and indices. Regarding PA the categories used in the present analysis aimed to characterize those who were mainly sedentary (Low PA) as opposed who those who are physical active to some extent (Intermediate PA) and those who reached or almost reached the WHO recommendations for PA (High PA) [17]. SRH were dichotomised, to define the group who reported good health compared to those who indicated poorer health [30-32]. For QoL the steps of the ladder of life were dichotomised, in common with other studies in this area into the groups of low QoL and high QoL [34, 35]. Furthermore economic situation was dichotomised into two groups based on self-reported information indicating problems or no problems with their economic situation. The three groups for education were defined to construct three broad categories of educational level, commonly used in Swedish context.

To reduce the risk of confounding we adjusted the analyses for sex, age, smoking habits, and diet quality Further participants who had had a myocardial infarction or stroke, angina pectoris, chronic lung disease, rheumatoid arthritis, muscle disease, neurological disease or depression were excluded, due to the possibility that the disease may have a negative impact on their ability to be physically active and may also be related to SRH and QoL. The target sample was randomly drawn from a general population. Although the response rate was low with $42 \%$ of the invited persons participating in the health dialogue and $56 \%$ of these also accepted an invitation to participate in the LSH study, the study sample is representative compared with the population in the southeast part of Sweden [60]. Also in the LSH study 72\% reported good SRH compared to $73 \%$, in a national survey [24]. In the LSH study 7\% of participants were daily smokers compared to $10 \%$ percent in the national survey, $64 \%$ had high PA in LSH compared to $65 \%$ in the national survey [24]. Finally this is a cross-sectional study and we can therefore not draw conclusions about causal relationships, [61]. To further explore and confirm our findings future longitudinal or intervention studies are needed.

\section{Conclusions}

In this population-based study of a middle-aged population we found that a high level of PA to a large degree could compensate for the negative impact from low SES in terms of economic problems and low education on SRH. For QoL the findings were not as consistent. The findings support the importance of promoting PA to reduce $\mathrm{SES}$ inequalities in $\mathrm{SRH}$ and with a potential to enhance QoL. However, as these findings are built on observational data, longitudinal or intervention studies are needed to further explore and confirm these assumptions.

\section{Additional files}

Additional file 1: Questions about your physical activity. (DOCX $110 \mathrm{~kb}$ )

Additional file 2: Associations between socioeconomic status and outcome variables stratified by PA level. (DOCX 18 kb)

\section{Abbreviations}

CVD: cardiovascular disease; LSH: Living Condition Stress and Health; OR: odds ratios; PA: physical activity; PHCC: primary health care centre; QoL: quality-of-life; SES: socioeconomic status; SRH: self-rated health

\section{Acknowledgments}

Not applicable.

\section{Funding}

The Unit for Research and Development in Primary Health Care, Futurum Academy for Health and Care, Region Jönköping County, Sweden funded the study. The Swedish Research Council and the Swedish Heart and Lung Foundation funded the LSH study.

Availability of data and materials

Please contact author for data requests.

Authors' contributions

$L J$ analysed and interpreted the patient data. All authors were contributors in writing the manuscript and had read and approved the final manuscript

Ethics approval and consent to participate

The study received ethical approval from the regional ethical review board in Linköping (\# 2012/336-32). All participants were properly informed about all study procedures and they gave written informed consent to participate in the study. The study is conducted in accordance with the guidelines of the Declaration of Helsinki.

\section{Consent for publication}

Consent for publication is included in the informed written consent to participate in the study.

\section{Competing interests}

The authors declare that they have no competing interests.

\section{Publisher's Note}

Springer Nature remains neutral with regard to jurisdictional claims in published maps and institutional affiliations.

\section{Author details}

${ }^{1}$ Unit for Research and Development in Primary Health Care, Futurum Academy for Health and Care, Region Jönköping County, Jönköping, Sweden. ${ }^{2}$ Linköping University, Linköping, Sweden. ${ }^{3}$ The A.D.U.L.T Research Group, School of Health and Welfare, Jönköping University, Jönköping, Sweden. ${ }^{4}$ Child Research Group, School of Health and Welfare, Jönköping University, Jönköping, Sweden. ${ }^{5}$ Unit for Community Medicine, Department of Medicine and Health, Linköping University, Linköping, Sweden. ${ }^{6}$ The A.D.U.L.T Research Group, Department of Natural Science and Biomedicine, School of Health and Welfare, Jönköping University, Jönköping, Sweden.

Received: 14 June 2018 Accepted: 24 January 2019

Published online: 08 February 2019

\section{References}

1. Olafsdottir S, Beckfield J, Bakhtiari E. Contextualizing disparities: the case for comparative research on social inequalities in health. Res Sociol Health Care. 2013:31:299-317.

2. Dong WL, Li YC, Wang ZQ, Jiang YY, Mao F, Qi L, Dong JQ, Wang LM. Self-rated health and health-related quality of life among Chinese residents, China, 2010. Health Qual Life Outcomes. 2016;14:5.

3. Beckfield J, Olafsdottir S, Bakhtiari E. Health inequalities in global context. Am Behav Sci. 2013;57:1014-39. 
4. Kunst AE, Bos V, Lahelma E, Bartley M, Lissau I, Regidor E, Mielck A, Cardano M, Dalstra JA, Geurts JJ, et al. Trends in socioeconomic inequalities in selfassessed health in 10 European countries. Int J Epidemiol. 2005;34:295-305.

5. Chen Y, Sun G, Guo X, Chen S, Chang Y, Li Y, Sun Y. Factors affecting the quality of life among Chinese rural general residents: a cross-sectional study. Public Health. 2017:146:140-7.

6. Burkert NT, Freidl W, Muckenhuber J, Grossschadl F, Stronegger WJ, Rasky E. Social status as a mediator of self-perceived health, quality of life and health-related behaviour in obesity. Gesundheitswesen. 2013;75:e101-7.

7. Granstrom F, Molarius A, Garvin P, Elo S, Feldman I, Kristenson M. Exploring trends in and determinants of educational inequalities in self-rated health. Scand J Public Health. 2015;43:677-86.

8. Johansson SE, Midlov P, Sundquist J, Sundquist K, Calling S. Longitudinal trends in good self-rated health: effects of age and birth cohort in a 25-year follow-up study in Sweden. Int J Public Health. 2015;60:363-73

9. Delpierre C, Kelly-Irving M, Munch-Petersen M, Lauwers-Cances V, Datta GD, Lepage B, Lang T. SRH and HrQOL: does social position impact differently on their link with health status? BMC Public Health. 2012;12:19.

10. Hasson D, Arnetz BB, Theorell T, Anderberg UM. Predictors of self-rated health: a 12-month prospective study of IT and media workers. Popul Health Metrics. 2006;4:8.

11. Kristenson M, Olsson AG, Kucinskiene Z. Good self-rated health is related to psychosocial resources and a strong cortisol response to acute stress: the LiVicordia study of middle-aged men. Int J Behav Med. 2005;12:153-60

12. Reile $R$, Stickley A, Leinsalu M. Large variation in predictors of mortality by levels of self-rated health: results from an 18-year follow-up study. Public Health. 2017;145:59-66.

13. Xie G, Zou H, Myint PK, Shi P, Ren F, Gao W, Wu Y. Baseline overall healthrelated quality of life predicts the 10-year incidence of cardiovascular events in a Chinese population. Qual Life Res. 2016;25:363-71.

14. Liang JW, Cheung YK, Willey JZ, Moon YP, Sacco RL, Elkind MSV, Dhamoon MS. Quality of life independently predicts long-term mortality but not vascular events: the northern Manhattan study. Qual Life Res. 2017;26:2219-28.

15. Caspersen CJ, Powell KE, Christenson GM. Physical activity, exercise, and physical fitness: definitions and distinctions for health-related research. Public Health Rep. 1985;100:126-31.

16. WHO: Action plan for implementation of the European strategy for the prevention and control of noncommunicable Diseases 2012-2016. Retrieved 2017-06-15 from http://www.euro.who.int/en/health-topics/ noncommunicable-diseases/cancer/publications/2012/action-plan-forimplementation-of-the-european-strategy-for-the-prevention-and-control-ofnoncommunicable-diseases-20122016 2012.

17. WHO: Global recommendations on physical activity for health. Retrieved 2017-03-16 from https://www.who.int/ncds/prevention/physical-activity/ guidelines-global-recommendations-for-health/en/ 2010.

18. Reddigan Il, Ardern Cl, Riddell MC, Kuk JL. Relation of physical activity to cardiovascular disease mortality and the influence of cardiometabolic risk factors. Am J Cardiol. 2011;108:1426-31.

19. Herman K, Hopman W, Vandenkerkhof E, Rosenberg M. Physical activity, body mass index, and health-related quality of life in Canadian adults. Med Sci Sports Exerc. 2012;44:625-36.

20. Sargent-Cox K, Cherbuin N, Morris L, Butterworth P, Anstey K. The effect of health behavior change on self-rated health across the adult life course: a longitudinal cohort study. Prev Med. 2014;58:75-80.

21. Bergland A, Thorsen $H$, Karesen R. Effect of exercise on mobility, balance, and health-related quality of life in osteoporotic women with a history of vertebral fracture: a randomized, controlled trial. Osteoporos Int. 2011; 22:1863-71

22. Lundqvist S, Borjesson M, Larsson ME, Hagberg L, Cider A. Physical activity on prescription (PAP), in patients with metabolic risk factors. A 6-month follow-up study in primary health care. PLoS One. 2017;12:e0175190.

23. WHO: Physical activity. Retrieved 2017-03-16, from http://www.who.int/ mediacentre/factsheets/fs385/en/ 2017.

24. The Public Health Agency of Sweden: Public health development -year report 2017. 2017.

25. Omorou AY, Coste J, Escalon H, Vuillemin A. Patterns of physical activity and sedentary behaviour in the general population in France: cluster analysis with personal and socioeconomic correlates. J Public Health. 2016;38:483-92
26. Niedzwiedz CL, Pell JP, Mitchell R. The relationship between financial distress and life-course socioeconomic inequalities in well-being: cross-National Analysis of European welfare states. Am J Public Health 2015;105:2090-8.

27. Persson LG, Lindstrom K, Lingfors H, Bengtsson C, Lissner L. Cardiovascular risk during early adult life. Risk markers among participants in "live for life" health promotion programme in Sweden. J Epidemiol Community Health. 1998:52:425-32.

28. Lingfors $H$, Lindstrom K, Persson LG, Bengtsson C, Lissner L. Evaluation of "live for life", a health promotion programme in the county of Skaraborg, Sweden. J Epidemiol Community Health. 2001;55:277-82.

29. Lingfors $H$, Lindstrom K, Persson LG, Bengtsson C, Lissner L. Lifestyle changes after a health dialogue. Results from the live for life health promotion programme. Scand J Prim Health Care. 2003;21:248-52.

30. Stadin M, Nordin M, Brostrom A, Magnusson Hanson LL, Westerlund H, Fransson El. Information and communication technology demands at work: the association with job strain, effort-reward imbalance and self-rated health in different socio-economic strata. Int Arch Occup Environ Health. 2016:89:1049-58.

31. Zajacova $\mathrm{A}$, Woo $\mathrm{H}$. Examination of age variations in the predictive validity of self-rated health. The Journals of Gerontology: Series B. 2016;71:551-7.

32. Pold M, Parna K, Ringmets I. Trends in self-rated health and association with socioeconomic position in Estonia: data from cross-sectional studies in 1996-2014. Int J Equity Health. 2016;15:200.

33. Cantril H: The Pattern of Human Concerns. New Brunswick, NJ: Rutgers, the University Press.; 1965.

34. Aasprang A, Andersen JR, Vage V, Kolotkin RL, Natvig GK. Psychosocial functioning before and after surgical treatment for morbid obesity: reliability and validation of the Norwegian version of obesity-related problem scale. PeerJ. 2015;3:e1275.

35. Levin KA, Currie C. Reliability and validity of an adapted version of the Cantril ladder for use with adolescent samples. Soc Indic Res. 2014;119: 1047-63.

36. Osborn CY, Kripalani S, Goggins KM, Wallston KA. Financial strain is associated with medication nonadherence and worse self-rated health among cardiovascular patients. J Health Care Poor Underserved. 2017; 28:499-513.

37. Wu S, Wang R, Zhao Y, Ma X, Wu M, Yan X, He J. The relationship between self-rated health and objective health status: a population-based study. BMC Public Health. 2013;13:320.

38. Kahneman D, Deaton A. High income improves evaluation of life but not emotional well-being. Proc Natl Acad Sci U S A. 2010;107:16489-93.

39. Trachte F, Geyer S, Sperlich S. Impact of physical activity on self-rated health in older people: do the effects vary by socioeconomic status? J Public Health (Oxf). 2016;38:754-9.

40. Erickson KI, Voss MW, Prakash RS, Basak C, Szabo A, Chaddock L, Kim JS, Heo S, Alves H, White SM, et al. Exercise training increases size of hippocampus and improves memory. Proc Natl Acad Sci U S A. 2011;108: 3017-22.

41. Oppezzo M, Schwartz DL. Give your ideas some legs: the positive effect of walking on creative thinking. J Exp Psychol Learn Mem Cogn. 2014; 40:1142-52

42. Yu CA, Rouse PC, Van Zanten JV, Metsios GS, Ntoumanis N, Kitas GD, Duda JL. Motivation-related predictors of physical activity engagement and vitality in rheumatoid arthritis patients. Health Psychol Open. 2015;2:2055102915600359.

43. Agudelo Leandro Z, Femenía T, Orhan F, Porsmyr-Palmertz M, Goiny M, Martinez-Redondo V, Correia Jorge C, Izadi M, Bhat M, Schuppe-Koistinen I, et al. Skeletal muscle PGC-1a1 modulates kynurenine metabolism and mediates resilience to stress-induced depression. Cell. 2014;159:33-45.

44. Pavey TG, Burton NW, Brown WJ. Prospective relationships between physical activity and optimism in young and mid-aged women. J Phys Act Health. 2015:12:915-23.

45. Tozzi L, Carballedo A, Lavelle G, Doolin K, Doyle M, Amico F, McCarthy H, Gormley J, Lord A, O'Keane V, Frodl T. Longitudinal functional connectivity changes correlate with mood improvement after regular exercise in a dose-dependent fashion. Eur J Neurosci. 2016;43:1089-96.

46. Mammen G, Faulkner G. Physical activity and the prevention of depression: a systematic review of prospective studies. Am J Prev Med. 2013;45:649-57.

47. Monma T, Takeda F, Okura T. Physical activities impact sense of coherence among community-dwelling older adults. Geriatr Gerontol Int. 2017;17: 2208-15. 
48. Eriksson M, Lindstrom B. A salutogenic interpretation of the Ottawa charter. Health Promot Int. 2008:23:190-9.

49. Mittelmark MB, Sagy S, Eriksson M, Bauer GF, Pelikan JM, Lindström B, Espnes GA. The handbook of Salutogenesis. Cham: Springer International Publishing; 2017.

50. Eriksson M. Salutogenes: om hälsans ursprung: [från forskning till praktisk tillämpning]. Stockholm: Liber; 2015.

51. Higgins TJ, Middleton KR, Winner L, Janelle CM. Physical activity interventions differentially affect exercise task and barrier self-efficacy: a meta-analysis. Health Psychol. 2014;33:891-903.

52. Lingfors $\mathrm{H}$. Prevention of ischaemic heart disease in primary health care. Experiences from a health promotion programme thesis. Göteborg: Göteborg University; 2003.

53. WHO: Health interview surveys: towards international harmonization of methods instruments. WHO office for Europe Copenhagen; 1996.

54. Lingfors $\mathrm{H}$, Lindström K, Persson LG, Bengtsson C, Lissner L, Ellegård L, Andersson $\mathrm{H}$. Evaluation of a pedagogic dietary questionnaire aimed for health surveys. Scand J Nutr. 1994;38:106-11.

55. The National Bord of Health and Welfare. Sjukdomsförebyggande metoder, (Disease Prevention Methods). Västerås: National border of health and welfare; 2011.

56. Buunk AP, Bennenbroek FT, Stiegelis HE, van den Bergh AC, Sanderman R, Hagedoorn M. Follow-up effects of social comparison information on the quality of life of cancer patients: the moderating role of social comparison orientation. Psychol Health. 2012;27:641-54.

57. Murdaugh C, Moneyham L, Jackson K, Phillips K, Tavakoli A. Predictors of quality of life in HIV-infected rural women: psychometric test of the chronic illness quality of life ladder. Qual Life Res. 2006;15:777-89.

58. Bailey D, Kazer M, Polascik T, Robertson C. Psychosocial trajectories of men monitoring prostate-specific antigen levels following surgery for prostate Cancer. Oncol Nurs Forum. 2014;41:361-8.

59. Baker F, Zabora J, Jodrey D, Polland A, Marcellus D. Quality of life and social support of patients being evaluated for bone marrow transplantation. J Clin Psychol Med Settings. 1995;2:357-72.

60. Statistics Retrived 180310 https://www.scb.se/.

61. Levin KA. Study design III: cross-sectional studies. Evid Based Dent. 2006;7:24-5.

Ready to submit your research? Choose BMC and benefit from:

- fast, convenient online submission

- thorough peer review by experienced researchers in your field

- rapid publication on acceptance

- support for research data, including large and complex data types

- gold Open Access which fosters wider collaboration and increased citations

- maximum visibility for your research: over $100 \mathrm{M}$ website views per year

At BMC, research is always in progress.

Learn more biomedcentral.com/submissions 